\title{
Value of follicular fluid vitamin $D$ in predicting the pregnancy rate in an IVF program
}

\author{
Razieh Dehghani Firouzabadi • Elham Rahmani • \\ Mozhgan Rahsepar • Mohammad Mahdavi Firouzabadi
}

Received: 11 October 2012/ Accepted: 5 July 2013/Published online: 24 July 2013

(C) Springer-Verlag Berlin Heidelberg 2013

\begin{abstract}
Purpose This study investigated whether there is a correlation between levels of $25 \mathrm{OH}-\mathrm{D}$ in the follicular fluid and the serum of infertile women and the results of IVF and rates of pregnancy. The association between the levels of $25 \mathrm{OH}-\mathrm{D}$ in the follicular fluid and the vitamin D repletion status was also assessed.

Methods Two hundred and twenty-one infertile women participated in an IVF cycle from 2010 to 2011 in a prospective observational study. Serum and follicular fluid were collected for vitamin D analysis. Deficient, insufficient, and sufficient levels of vitamin D were defined as 10 , 10-29, and 30-100 ng/ml, respectively. IVF cycle parameters and clinical pregnancy rates were also compared with the vitamin D level.

Results The levels of vitamin D deficiency, insufficiency, and sufficiency were $22.6,70.1$, and $7.2 \%$, respectively. The fertilization rates associated with these three levels of vitamin D were $43.17,53.37$, and $58.77 \%$, respectively, $(P=0.054)$, and the implantation rates were $17.33,15.26$, and $18.75 \%$, respectively, $(P=0.579)$. No significant correlation was seen between the pregnancy rate and the serum vitamin $\mathrm{D}$ level $(P=0.094)$ or the follicular
\end{abstract}

R. D. Firouzabadi · M. Rahsepar

Yazd Research and Clinical Center for Infertility,

Shahid Sadoughi University of Medical Sciences,

Bouali Ave, Safaieh, 8916877391 Yazd, Iran

E. Rahmani ( $\square)$

Obstetrics and Gynecology Ward, Bushehr University

of Medical Sciences, Bushehr, Iran

e-mail: rahmani@bpums.ac.ir

M. M. Firouzabadi

Taft Shahid Beheshti Hospital, Shahid Sadoughi University

of Medical Sciences, Yazd, Iran vitamin D level $(P=0.170)$. The serum and follicular fluid vitamin D levels showed a significant correlation $(P=0.000)$.

Conclusion Although vitamin D is an important hormone in the human body, no correlation was found between the serum and follicular vitamin $\mathrm{D}$ level and the pregnancy rate in the IVF cycle.

Keywords Vitamin D · IVF · Follicular fluid .

Pregnancy rate $\cdot 250 \mathrm{H}-\mathrm{D}$

\section{Introduction}

Vitamin D plays important clinical roles in the human body thanks to its interrelationship with bone metabolism and calcium homeostasis [1]. Many cells in the human body contain vitamin D receptors. Given the interrelationship between bone metabolism and calcium homeostasis, any deficiency in vitamin D may result in several health risks. Many studies have addressed the association between vitamin D deficiency and an increased risk of cancer, autoimmune diseases, diabetes, rheumatoid arthritis, multiple sclerosis, and cardiac diseases [2].

Pregnant women with vitamin D deficiency show increased risks of pregnancy complications, such as preeclampsia [3] and bacterial vaginosis [4]. Vitamin D supplementation has been found to cause a $50 \%$ decrease in premature labor pains, a $25 \%$ reduction in bacterial vaginosis, and a $30 \%$ decline in diabetes, hypertension, and preeclampsia [5].

Heaney et al. [6] described the functions of vitamin D in a wide range of physiological processes. They found that it has a critical role in the regulation of cellular growth and metabolic modulations related to insulin. Vitamin D 
deficiency was also found to be associated with insulin resistance via a mechanism involving stimulation of the expression of insulin receptors. Research has also shown that the regulation of intra- and extracellular calcium and modulators have profound effects on the immune system [7].

Vitamin D is associated with steroidogenesis of estradiol and progesterone. Levels of the vitamin were reported to be increased in endometriosis [8]. The relationship between vitamin $\mathrm{D}$ and steroidogenesis was affected by calcium homeostasis and the direct regulation of the expression of the aromatase gene [9]. It was also reported that vitamin D regulates HOXA10 in the stromal cells of the endometrium and that this, is in turn, aids implantation and uterine receptivity [1].

Seasonal changes in vitamin D levels are known to influence endometrial and oocyte development [10]. Hypersensitivity to vitamin D can also occur. The most common example is primary hyperparathyroidism [11]. Limited data suggest that excessive serum and follicular vitamin D negatively affect IVF [12]. Further clarification is needed on the relationship between vitamin $\mathrm{D}$ and IVF outcomes. Previous studies assessed vitamin D in IVF cycles using different protocols because different drugs have dissimilar effects on follicular fluid substances [13]. This study aimed to demonstrate the role of vitamin $\mathrm{D}$ in Iranian patients undergoing IVF with one single protocol.

\section{Materials and methods}

In a prospective cohort study from September 2010 to September 2011, 221 patients were selected, and they provided informed consent to participate in the study. The study was approved by the Ethics Committee of Yazd Research and Clinical Center for Infertility of Shahid Sadoughi University of Medical Sciences. The inclusion criteria were acceptance of the standard long protocol, (Follicular stimulating hormone) FSH $<10$ (IU/L), and aged between 20 and 39 years. The exclusion criteria were liver, kidney, or heart disease; a severe male factor; endometriosis; Cushing's syndrome; hyper- or hypothyroidism; hyperprolactinemia; or a body mass index of more than $29 \mathrm{~kg} / \mathrm{m}^{2}$ or less than $18 \mathrm{~kg} / \mathrm{m}^{2}$. The primary outcome was chemical pregnancy, and the secondary outcome was the determination of follicular and serum vitamin D levels. All the patients received the long protocol, starting with $0.5 \mathrm{mg} /$ day of Buserelin Acetate (Suprefact, Aventis Pharma Deutschland, Germany) in the midluteal phase. After menstruation and the completion of pituitary suppression (FSH $\leq 5 \mathrm{IU} / \mathrm{ml}$, (Luteinizing Hormone) $\mathrm{LH} \leq 5 \mathrm{IU} / \mathrm{ml}$, estradiol $\leq 50 \mathrm{pg} / \mathrm{ml}$, and progesterone $\leq 1 \mathrm{ng} / \mathrm{ml}$ ), Suprefact was decreased to
$0.25 \mathrm{mg} /$ day and continued until the day of ovum pick-up. Gonal-F (Gonal-F, Serono, Italy) was initiated from the second day of menses according to the patient's age and antral follicular count. The dose of Gonal-F was adjusted by sonography and estradiol. The sonography was conducted on the seventh day and repeated as needed. When the follicular size reached 18-20 mm, HCG (Pregnyl, Daropakhsh, Iran) 10,000 IU was administered. After 34-36 h, transvaginal ultrasound-guided ovum pick-up was performed. On the day of ovum pick-up, follicular fluid was collected from follicles more than $14 \mathrm{~mm}$. Serum samples were obtained to determine the level of vitamin D. The sera were separated by centrifugation, and the samples were frozen at $-20^{\circ} \mathrm{C}$. When all the samples had been collected, vitamin $\mathrm{D}$ was assayed. The vitamin D was checked by enzyme immunoassay (25-hydroxy vitamin D EIA kit, IDS Ltd., Cat. Nos.: AC-57F1 and AC-57F2, UK). Meanwhile, high-quality fresh embryos (i.e., seven or more blastomeres on day three with $20 \%$ fragmentation or less) were transferred on the third day after intracytoplasmic sperm injection by Labotect catheter (Labotect, Gotting, Germany). The luteal phase was supported by $400 \mathrm{mg}$ of Cyclogest (Actavis, Barnstaple, and UK) vaginally two times per day. The administration started on the day after the oocyte was retrieved. The serum $\beta \mathrm{hCG}$ was also checked 14 days after the embryo transfer. In case of pregnancy, Cyclogest was continued until the tenth week of gestation. Clinical pregnancy was confirmed by transvaginal sonography with at least one gestational sac in the uterine cavity. Serum vitamin D levels were defined as deficient $(<10 \mathrm{ng} / \mathrm{ml})$, insufficient $(10-29 \mathrm{ng} / \mathrm{ml})$, or sufficient $(30-100 \mathrm{ng} / \mathrm{ml})$. If the patients had any adverse reactions' they were kept under close observation and management at the study center.

The data were analyzed using the SPSS version 16 computer program. The continuous variables were determined as the mean \pm standard deviation or median values. The normality of quantitative data was assessed by histogram and the one sample Kolmogorov-Smirnov test. As the continuous data had a non-parametric distribution, the data of the two groups were compared using the MannWhitney $U$ test. A Chi-square was used to compare the qualitative variables where variables had a normal distribution; an independent sample $t$ test was used to adjust the age and FSH of the patients. The Mann-Whitney test was used to adjust the duration of infertility, etiology, LH, Thyroid stimulating hormone (TSH), Prolactin, and estradiol of the patients and to compare the numbers of their oocytes and embryos and their endometrial thickness. A Chi-square test was also carried out to compare the numbers of follicles and embryo transfers and the doses of gonadotropin administered to the patients. Spearman's correlation test was utilized to determine the relationship between the serum and follicular fluid vitamin D. 
Moreover, a Kruskal-Wallis test was employed to measure the fertilization and implantation rates based on the vitamin D level. $P$ values $<0.05$ were considered significant. The final study comprised 180 patients, with the confidence interval set at $95 \%$, the power at $80 \%$, the prevalence of vitamin D deficiency about $60 \%$, and the error at $10 \%$.

\section{Results}

The subjects of this study were 221 women. The patients' demographic characteristics are described in Tables 1 and 2. The vitamin $D$ in the serum was at an insufficient level in 155 patients $(75.1 \%)$, at a deficient level in 50 patients $(22.6 \%)$, and at a sufficient level in 16 patients $(7.2 \%)$ (Fig. 1). Among all the patients, $74(33.48 \%)$ had a positive clinical pregnancy. The pregnant group was compared with the non-pregnant group in terms of the level of vitamin $\mathrm{D}$ in the serum (Table 3). There was no significant difference between the two groups (Pearson Chisquare, $P=0.094)$. The level of vitamin $\mathrm{D}$ in the follicular fluid of the pregnant group was $22.17 \pm 17.21 \mathrm{ng} / \mathrm{ml}$. It was $26.14 \pm 19.33 \mathrm{ng} / \mathrm{ml}$ in the non-pregnant group. However, this difference was not significant (MannWhitney test, $P=0.17$ ) (Fig. 2). The correlation between the vitamin D levels in the serum and in the follicular fluid was calculated using Spearman's test. A correlation of $r=0.83$ showed that the result was significant $(P=0.001)$ (Fig. 3), with the follicular vitamin D directly reflecting the stocks of the vitamin in the body. Goodquality embryos in the deficient, insufficient, and sufficient groups occurred at rates of 82.6, 90.2, and $86.7 \%$, respectively. There was no significant difference between the various levels of vitamin D $(P=0.372)$. The fertilization rates in the deficient, insufficient, and sufficient groups were 43.17, 53.37, and $58.77 \%$, respectively, (Kruskal-Wallis $H$ test, $P=0.054$ ), and the implantation rates were $17.33,15.26$, and $18.75 \%$, respectively. There was no significant difference between the results (KruskalWallis $H$ test, $P=0.579$ ) (Table 4).

\section{Discussion}

The results demonstrated that there was no correlation between the amount of vitamin D in serum and follicular fluid and IVF outcomes, although Anifandis and Ozkan $[12,14]$ reported a direct association between vitamin $D$ levels and IVF success. Rudick et al. [15] demonstrated that deficiency in vitamin $\mathrm{D}$ resulted in lower pregnancy rates for non-Asian patients but not for Asian patients. They added that the lack of association between vitamin $D$ levels and IVF success in Asian patients was probably due to the fact that they had lower IVF pregnancy rates. The current study of Asian patients found the same results. Rudick et al. [16] also suggested that vitamin D deficiency was not associated with the number of follicles and oocytes or with the morphology of the embryo. Another study suggested that the effect of this deficiency on the pregnancy rate may be realized through the endometrium. In a similar study, Aleyasin et al. [17] suggested that vitamin D deficiency had no correlation with IVF outcomes. Estes et al. [18] demonstrated that proteomic analysis of follicular fluid had potential as a biomarker of good responders versus poor responders in IVF. The current study found that vitamin D in the follicular fluid was the same in the pregnant and non-pregnant groups.
Table 1 Demographic characteristic of patients and IVF outcomes
$P$ values $<0.05$ was significant

a Median, comparison was performed by Student's $t$ test or Mann-Whitney test as appropriate

\begin{tabular}{llll}
\hline & $\begin{array}{l}\text { Pregnant group } \\
N=74(33.48 \%) \\
\text { Mean } \pm \mathrm{SD}\end{array}$ & $\begin{array}{l}\text { Non-pregnant group } \\
N=147(66.51 \%)\end{array}$ & $P$ value \\
\hline Age (years) & $29.1 \pm 4.67$ & $29.51 \pm 4.77$ & 0.873 \\
Duration of infertility (years) & $6.53 \pm 4.54$ & $7.01 \pm 4.53$ & 0.306 \\
FSH (IU/L) & $6.07 \pm 2.15$ & $6.07 \pm 1.86$ & 0.998 \\
LH (IU/L) & $5.56 \pm 4.07$ & $5.31 \pm 3.79$ & 0.768 \\
TSH ( $\mu / \mathrm{L})$ & $2.26 \pm 1.84$ & $2.4 \pm 1.32$ & 0.847 \\
Prolactin (ng/mL) & $18.23 \pm 10.26$ & $17.19 \pm 9.06$ & 0.614 \\
Estradiol on day of HCG $(\mathrm{pg} / \mathrm{ml})$ & $1,000^{\mathrm{a}}$ & $1,100^{\mathrm{a}}$ & 0.449 \\
Number of follicles $(n)$ & $11.71 \pm 7.41$ & $10.73 \pm 5.78$ & 0.321 \\
Number of oocytes $(n)$ & $9.75 \pm 7.4$ & $8.39 \pm 5.2$ & 0.343 \\
Total number of embryos $(n)$ & $4.73 \pm 3.46$ & $3.9 \pm 3.04$ & 0.041 \\
Total number of embryo transfers $(n)$ & $2.3 \pm 0.56$ & $2.21 \pm 0.75$ & 0.389 \\
Total dose of gonadotropin $(\mathrm{IU})$ & $2253.04 \pm 745.8$ & $2356.63 \pm 722.4$ & 0.326 \\
Endometrial thickness $(\mathrm{mm})$ & $9.82 \pm 1.59$ & $9.49 \pm 1.63$ & 0.221 \\
\hline
\end{tabular}


Table 2 Etiology of infertility in the patients

\begin{tabular}{lccc}
\hline $\begin{array}{l}\text { Etiology of } \\
\text { infertility }\end{array}$ & $\begin{array}{l}\text { Pregnant } \\
\text { patients }(\%)\end{array}$ & $\begin{array}{l}\text { Non-pregnant } \\
\text { patients (\%) }\end{array}$ & $P$ value \\
\hline Male factor & $36(48.6 \%)$ & $81(55.1 \%)$ & \\
Tubal factor & $14(18.9 \%)$ & $13(8.8 \%)$ & \\
Endometriosis & $3(4.1 \%)$ & $8(5.4 \%)$ & \\
$\begin{array}{l}\text { Poly cystic ovarian } \\
\text { syndrome }\end{array}$ & $11(14.9 \%)$ & $21(14.3 \%)$ & 0.748 \\
Unexplained infertility & $10(13.5 \%)$ & $24(16.3 \%)$ & \\
Total patients & $74(33.48 \%)$ & $147(66.51 \%)$ & \\
\hline
\end{tabular}

Mann-Whitney test, $P$ values $<0.05$ was significant

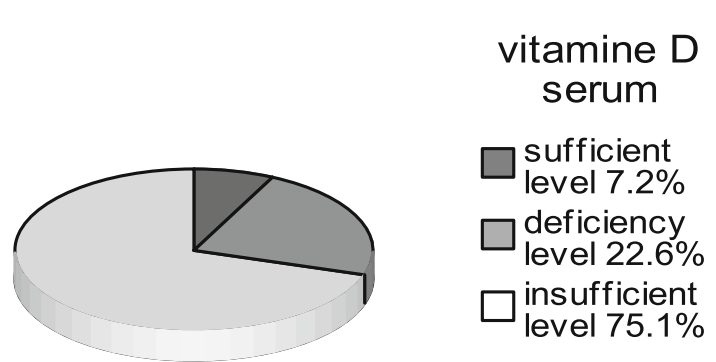

Fig. 1 Prevalence of vitamin D in the study group

Table 3 Comparison of vitamin D levels in both groups

\begin{tabular}{lllll}
\hline Groups & \multicolumn{2}{l}{ Vitamin D } & $P$ value \\
\cline { 2 - 4 } & $<10 \mathrm{ng} / \mathrm{ml}$ & $10-29 \mathrm{ng} / \mathrm{ml}$ & $30-100 \mathrm{ng} / \mathrm{ml}$ & \\
\hline Pregnant & $23(31.1 \%)$ & $47(63.5 \%)$ & $4(5.4 \%)$ & 0.094 \\
Non-pregnant & $27(18.4 \%)$ & $108(73.5 \%)$ & $12(8.2 \%)$ & \\
\hline
\end{tabular}

Correlation between vitamin D and pregnancy by Pearson Chi-square

$P$ value $<0.05$ was significant

Vitamin D has a variety of functions, including the stimulation of ovarian steroidogenesis and the production of Insulin-like growth factor-binding protein-1 (IGFBP-1) in ovarian cells through vitamin $\mathrm{D}$ receptors. Insulin and vitamin D stimulate estradiol, estrone, and progesterone production. Vitamin D also improves the inhibitory effect of insulin on IGFBP-1 production [19]. Therefore, if there is an increase in the level of vitamin D and a decrease in the level of glucose follicular fluid, it will have a negative effect on the embryo score [12]. Vitamin D induces the transcription of HOXA10 (an important gene for implantation) through vitamin $\mathrm{D}$ receptors. Treatment with vitamin D increases mRNA and protein expression of HOXA10. Vitamin D also has a direct impact on the regulation of HOXA10, and this has implications for fertility [20]. Ozkan et al. [14] referred to this effect in their research study. They reported that normal vitamin D levels in serum improve the IVF outcome. They further proposed that excess vitamin concentrations play a decisive role in

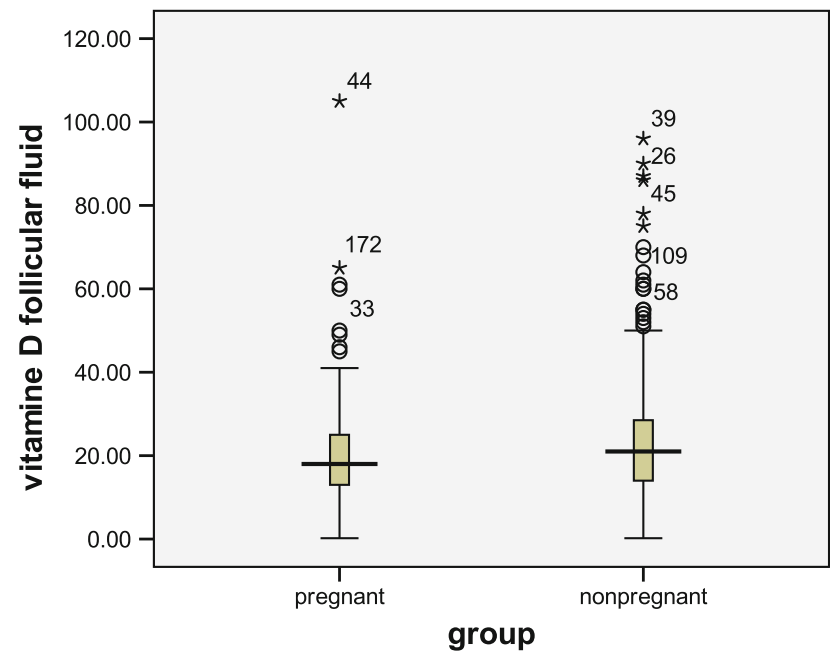

Fig. 2 Correlation of follicular vitamin D and pregnancy. MannWitney test, $P$ value $=0.17$ was not significant

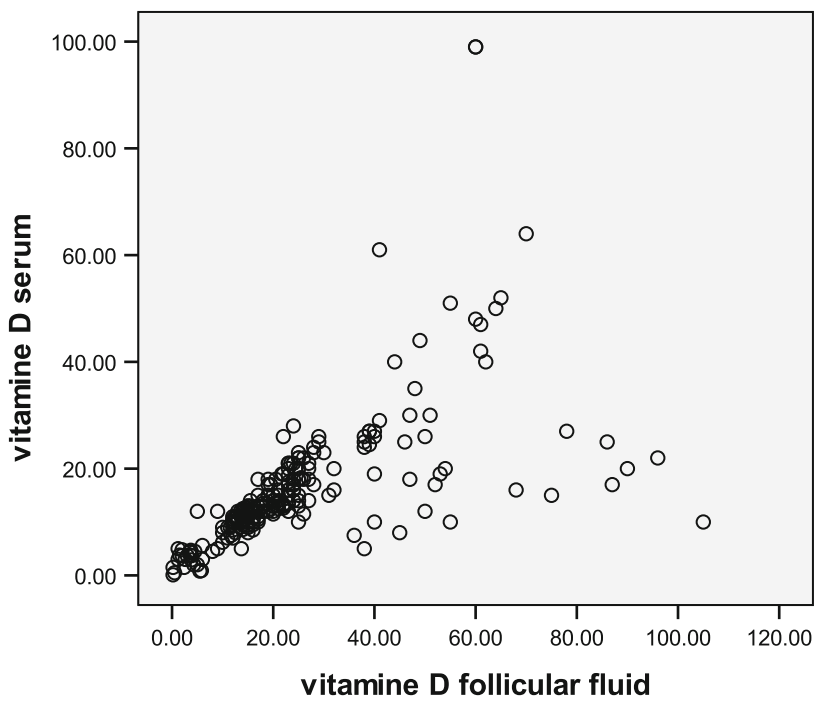

Fig. 3 Correlation of follicular and serum vitamin D. Spearman correlation, $r=0.83 ; P$ value $=0.001$

Table 4 Comparison of fertilization and implantation rate according to vitamin D level

\begin{tabular}{lllll}
\hline & Vitamin D & P value \\
\cline { 2 - 4 } & $\begin{array}{l}\text { Deficient } \\
\text { level }\end{array}$ & $\begin{array}{l}\text { Insufficient } \\
\text { level }\end{array}$ & $\begin{array}{l}\text { Sufficient } \\
\text { level }\end{array}$ & \\
\hline $\begin{array}{l}\text { Fertilization } \\
\text { rate }\end{array}$ & $43.17 \%$ & $53.37 \%$ & $58.77 \%$ & 0.054 \\
$\begin{array}{l}\text { Implantation } \\
\text { rate }\end{array}$ & $17.33 \%$ & $15.26 \%$ & $18.75 \%$ & 0.579 \\
\hline
\end{tabular}

Kruskal-Wallis $H$ Test, $P$ value $<0.05$ not significant

endometrial receptivity because $25-\mathrm{OH}$ vitamin D receptors were identified in the endometrium [14]. Rudick et al. [16] stated that vitamin D may have an effect on the 
endometrium in donor-recipient patients. However, this idea seems to be in contrast with the finding of decreased expression of the vitamin D binding protein in the follicular fluid of an IVF success group reported by Estes et al. [17].

Vitamin D has also been reported to be related to obesity and to endocrine and metabolic factors in polycystic ovarian syndrome $[1,21,22]$. Vitamin D supplementation was shown to improve menstrual cycle disturbances and metabolic disturbances [23, 24]. Anifandis et al. [12] suggested that increased follicular fluid vitamin D concentrations $(>30 \mathrm{ng} / \mathrm{ml}$ ) can affect the action of insulin, resulting in the modulation of follicular fluid glucose metabolism. High serum levels of vitamin D may increase the consumption of insulin. This condition appears to be undesirable because it has a direct negative impact on oocyte maturation, the growth of granulosa and cumulus cells, and the embryo quality and consequently on the IVF outcome. Therefore, high and low levels of vitamin $\mathrm{D}$ have an adverse effect on the IVF cycle. It is noteworthy that due to time limitations, the number of patients who participated in this study was limited.

\section{Conclusion}

The prevalence of vitamin D insufficiency was very high among the patients who participated in this study. However, no significant correlation was found between pregnancy outcomes and vitamin D levels. These findings may be related to the sample size. However, in the group who had a sufficient level of vitamin D, there was a trend toward increased implantation and fertilization. All patients are advised to take vitamin D supplements due to benefits such as bone health, pregnancy health, and decreasing chronic diseases. There is scope for more research projects about vitamin D. Future research could include case-control studies of patients with vitamin D supplementation undergoing IVF treatment.

Acknowledgments The researchers wish to thank all the staff of Yazd Research and Clinical Center for Infertility for their invaluable and kind assistance in this research project. This study was supported by Shahid Sadoughi University of Medical Sciences.

Conflict of interest The authors certify that no actual or potential conflict of interest in relation to this article exists.

\section{References}

1. Lerchbaum E, Obermayer-Pietsch B (2012) Mechanisms in endocrinology: vitamin D and fertility: a systematic review. Eur J Endocrinol 166(5):765-778. doi:10.1530/eje-11-0984

2. Holick MF, Binkley NC, Bischoff-Ferrari HA, Gordon CM, Hanley DA, Heaney RP, Murad MH, Weaver CM (2011)
Evaluation, treatment, and prevention of vitamin D deficiency: an endocrine society clinical practice guideline. J Clin Endocrinol Metab 96(7):1911. doi:10.1210/jc.2011-0385

3. Barrett H, McElduff A (2010) Vitamin D and pregnancy: an old problem revisited. Best Pract Res Clin Endocrinol Metab 24(4):527-539. doi:10.1016/j.beem.2010.05.010

4. Bodnar LM, Krohn MA, Simhan HN (2009) Maternal vitamin D deficiency is associated with bacterial vaginosis in the first trimester of pregnancy. J Nutr 139(6):1157-1161. doi:10.3945/jn. 108.103168

5. Hollis BW, Johnson D, Hulsey TC, Ebeling M, Wagner CL (2011) Vitamin D supplementation during pregnancy: doubleblind, randomized clinical trial of safety and effectiveness. J Bone Miner Res 26(10):2341-2357. doi:10.1002/jbmr.463

6. Heaney RP (2008) Vitamin D in health and disease. Clin J Am Soc Nephrol 3(5):1535-1541. doi:10.2215/CJN.01160308

7. Zittermann A, Gummert JF (2010) Nonclassical vitamin D actions. Nutrients 2(4):408-425. doi:10.3390/nu2040408

8. Somigliana E, Panina-Bordignon P, Murone S, Di Lucia P, Vercellini P, Vigano P (2007) Vitamin D reserve is higher in women with endometriosis. Hum Reprod 22(8):2273. doi:10. 1093/humrep/dem142

9. Kinuta K, Tanaka H, Moriwake T, Aya K, Kato S, Seino Y (2000) Vitamin D is an important factor in estrogen biosynthesis of both female and male gonads. Endocrinology 141(4):13171324. doi:10.1210/en.141.4.1317

10. Reynolds K, Turley F, Abdallah M, Hofmann G (2010) Seasonal $25(\mathrm{OH}) \mathrm{D}$ levels in women of reproductive age. Fertil Steril 94(4):S91-S91. doi:10.1016/j.fertnstert.2010.07.352

11. Vieth R (1999) Vitamin D supplementation, 25-hydroxy vitamin D concentrations, and safety. Am J Clin Nutr 69(5):842-856

12. Anifandis GM, Dafopoulos K, Messini CI, Chalvatzas N, Liakos N, Pournaras S, Messinis IE (2010) Prognostic value of follicular fluid 25-OH vitamin D and glucose levels in the IVF outcome. Reprod Biol Endocrinol 8(1):91. doi:10.1186/14777827-8-91

13. Lee VC, Chan CC, Ng EH, Yeung WS, Ho PC (2011) Sequential use of letrozole and gonadotrophin in women with poor ovarian reserve: a randomized controlled trial. Reprod Biomed Online 23(3):380-388. doi:10.1016/j.rbmo.2011.05.012

14. Ozkan S, Jindal S, Greenseid K, Shu J, Zeitlian G, Hickmon C, Pal L (2010) Replete vitamin D stores predict reproductive success following in vitro fertilization. Fertil Steril 94(4):1314-1319. doi:10.1016/j.fertnstert.2009.05.019

15. Rudick B, Ingles S, Stanczyk F, Chung K, Paulson R, Bendikson $\mathrm{K}$ (2010) Characterizing the role of vitamin D levels on IVF outcomes: stimulation, embryo, or endometrium? Fertil Steril 94(4):S72. doi:10.1016/j.fertnstert.2010.07.280

16. Rudick B, Ingles S, Stanczyk F, Chung K, Paulson R, Bendikson $\mathrm{K}$ (2011) The role of vitamin D levels on IVF outcomes in donorrecipient cycles. Fertil Steril 95(4):S8. doi:10.1016/j.fertnstert. 2011.01.053

17. Aleyasin A, Hosseini MA, Mahdavi A, Safdarian L, Fallahi P, Mohajeri MR, Abbasi M, Esfahani F (2011) Predictive value of the level of vitamin D in follicular fluid on the outcome of assisted reproductive technology. Eur J Obstet Gynecol Reprod Biol 159(1):132-137. doi:10.1016/j.ejogrb.2011.07.006

18. Estes SJ, Ye B, Qiu W, Cramer D, Hornstein MD, Missmer SA (2009) A proteomic analysis of IVF follicular fluid in women $\leq 32$ years old. Fertil Steril 92(5):1569-1578. doi:10.1016/j. fertnstert.2008.08.120

19. Parikh G, Varadinova M, Suwandhi P, Araki T, Rosenwaks Z, Poretsky L, Seto-Young D (2010) Vitamin D regulates steroidogenesis and insulin-like growth factor binding protein-1 (IGFBP-1) production in human ovarian cells. Horm Metab Res 42(10):754-757. doi:10.1055/s-0030-1262837 
20. Du H, Daftary GS, Lalwani SI, Taylor HS (2005) Direct regulation of HOXA10 by $1,25-(\mathrm{OH}) 2 \mathrm{D} 3$ in human myelomonocytic cells and human endometrial stromal cells. Mol Endocrinol 19(9):2222-2233. doi:10.1210/me.2004-0336

21. Li HWR, Brereton RE, Anderson RA, Wallace AM, Ho CKM (2011) Vitamin D deficiency is common and associated with metabolic risk factors in patients with polycystic ovary syndrome. Metabolism 60(10):1475-1481. doi:10.1016/j.metabol.2011.03. 002

22. Yildizhan R, Kurdoglu M, Adali E, Kolusari A, Yildizhan B, Sahin HG, Kamaci M (2009) Serum 25-hydroxyvitamin D concentrations in obese and non-obese women with polycystic ovary syndrome. Arch Gynecol Obstet 280(4):559-563. doi:10.1007/ s00404-009-0958-7

23. Selimoglu H, Duran C, Kiyici S, Ersoy C, Guclu M, Ozkaya G, Tuncel E, Erturk E, Imamoglu S (2010) The effect of vitamin D replacement therapy on insulin resistance and androgen levels in women with polycystic ovary syndrome. J Endocrinol Invest 33(4):234-238

24. Rd Firouzabadi, Aflatoonian A, Modarresi S, Sekhavat L, MohammadTaheri S (2012) Therapeutic effects of calcium and vitamin D supplementation in women with PCOS. Compl Ther Clin Pract 18(2):85-88. doi:10.1016/j.ctcp.2012.01.005 